\title{
An investigation into the effect of scour on the natural frequency of an Offshore Wind Turbine
}

Prendergast, L.J. ${ }^{\mathrm{a}, 1}$, Gavin, K., ${ }^{\mathrm{a}, 2}$, Doherty, P., ${ }^{\mathrm{a}, 3}$

${ }^{a}$ School of Civil, Structural and Environmental Engineering, University College Dublin,

Newstead,

Belfield,

Dublin 4,

IRL

${ }^{1}$ Corresponding author

Phone: ${ }^{1}+353-1-7163231 /{ }^{2}+353-1-7163222$

Email: ${ }^{1}$ luke.prendergast@ucdconnect.ie, ${ }^{2}$ kenneth.gavin@ucd.ie, ${ }^{3}$ paul.doherty@ucd.ie

\begin{abstract}
Rapid expansion of the offshore wind industry has stimulated a renewed interest in the behaviour of offshore piles. There is widespread acceptance in practice that pile design methods developed for the offshore oil and gas industry may not be appropriate for designing wind turbine foundations. To date, the majority of offshore wind turbines are supported by large diameter monopiles. These foundations are sensitive to scour which can reduce their ultimate capacity and alter their dynamic response. In this paper, the use of a vibration-based method to monitor scour is investigated. The effect of scour on the natural frequency of a model monopile was measured in a scale model test. A spring-beam finite element numerical model was developed to examine the foundation response. The model, which used springs tuned to the small-strain stiffness of the sand, was shown to be capable of capturing the change in frequency observed in the scale test. This numerical procedure was extended to investigate the response of a full-scale wind turbine over a range of soil densities, which might be experienced at offshore development sites. Results suggest that wind turbines founded in loose sand would exhibit the largest relative reductions in natural frequency resulting from scour.
\end{abstract}

Keywords: Scour; Acceleration; Wind Turbines; Frequency; Soil Stiffness; Monopiles 


\subsection{Introduction}

The development of offshore wind energy converters is viewed as one of the most cost effective and politically acceptable short-term means of reducing society's reliance on fossil fuels. Since 1991, the majority (over 75\%) of offshore wind turbines have been founded on large diameter steel tubular monopiles (EWEA, 2012). These piles with diameters $\left(D_{\text {pile }}\right)$ in the range $4 \mathrm{~m}$ to $6 \mathrm{~m}$ are typically driven to penetrations ( $\mathrm{L}_{\text {embed }}$ ) of between 20 - $30 \mathrm{~m}$ (Doherty and Gavin, 2012). The resulting piles are relatively stiff, with low slenderness $\left(\mathrm{L}_{\text {embed }} / \mathrm{D}_{\text {pile }}\right)$ ratios. Monopile design is usually performed using spring-beam (p-y) models which are described in the American Petroleum Institute (API, 2007) and Det Norske Veritas (Det Norske Veritas, 2007) design codes. The design should consider all limit states including the ultimate limit state (ULS). However, because of strict rotational tolerance specifications, serviceability requirements tend to govern design.

Wind turbines are dynamically sensitive structures with the primary excitation forces arising from the rotor spinning at a given rotational velocity, termed the $1 \mathrm{P}$ frequency and the blade passing frequency, termed $\mathrm{N}_{b} \mathrm{P}$, where $\mathrm{N}_{b}$ is the number of blades on the turbine. LeBlanc et al. (2010) note that typical ranges for the 1P frequency are 0.17 to $0.33 \mathrm{~Hz}$, whilst for a standard three bladed turbine; 3P is in the range 0.5 to $1 \mathrm{~Hz}$ (see Fig. 1). Wind and wave frequencies are typically below the $1 \mathrm{P}$ frequency, although wave frequencies are highly variable and can span a relatively wide frequency spectrum, see Tempel and Molenaar (2002). During the design phase for the turbine support structure, it is important to minimise the potential dynamic amplification of the load and avoid resonance by ensuring that the natural system frequency of the turbine and its support system does not coincide with any of the excitation frequencies discussed above. This is achieved by tailoring the stiffness of the structural system at the foundation-superstructure interface through careful design of a sub-structure system. In terms of the foundation, a designer can choose a very stiff structure (termed stiff-stiff) such as a jacket, leading to a natural system frequency above the 3P range. Alternatively, a structure with a system frequency between the $1 \mathrm{P}$ and $3 \mathrm{P}$ values, termed a soft-stiff structure can be created by using a monopile foundation. It is possible to design a flexible structure, with a system frequency below 1P, termed a soft-soft structure. However, these soft-soft design options are susceptible to resonance from sea waves due to the alternating stresses induced on the structure by the period of passing waves.

It is widely recognised that offshore piles installed in non-cohesive deposits can be affected by local scour. Local scour occurs around piles when the near bed shear stresses exceed the critical shear stress at which sediment starts to move and occurs as a result of the installed pile changing the local waterflow characteristics (Peder Hyldal Sørensen and Bo Ibsen, 2013). The DNV design codes recommend that a local scour hole depth of 1.3 pile diameters $\left(1.3 \mathrm{D}_{\text {pile }}\right)$ should be considered for both the ultimate and serviceability limit state design cases in the case of a monopile subjected to current only-induced scour (Det Norske Veritas, 2007). In the marine environment however, it must be 
recognised that these structures can be jointly subjected to currents, tides and waves which makes the problem more complex than that of scour around structures in rivers (which are generally under steady current conditions) (Negro et al., 2014). It is also noteworthy that natural variation in seabed level over a large area can give rise to a further global scour effect, which could have an effect over an entire wind farm site leading to more severe scour depths. Under the action of waves, the expression for the equilibrium scour depth $\left(\mathrm{S}_{\mathrm{eq}}\right)$ around a tubular monopile as recommended by the DNV is shown in Eq. (1) (Det Norske Veritas, 2011; Peder Hyldal Sørensen and Bo Ibsen, 2013). This expression was derived by (Sumer et al., 1992) based on several small-scale tests.

$$
S_{e q}=1.3 D_{\text {pile }}\{1-\exp [-0.03(K C-6)]\}, \quad K C \geq 6
$$

where $\mathrm{KC}$ is the Keulegan-Carpenter number, a dimensionless parameter that is a function of the maximum horizontal particle velocity at still water level $\left(\mathrm{u}_{\max }\right)$, the intrinsic period of the waves $\left(\mathrm{T}_{\mathrm{i}}\right)$ and the monopile diameter $\left(\mathrm{D}_{\text {pile }}\right)$. The equilibrium scour depth increases as $\mathrm{KC}$ values increase and tends toward the current-only equilibrium scour depth for large KC values. Sumer and Fredsøe (2001) proposed a modification to Eq. (1) for the case of a pile subjected to combined steady current and waves. Their modification introduces a dimensionless parameter that describes whether currents or waves are dominating. In general, the design scour depth will be large when currents are dominating and small when waves are dominating (Peder Hyldal Sørensen and Bo Ibsen, 2013).

Uncertainties in the magnitude and variability of the various parameters governing the scour process can lead to difficulties in the accurate estimation of a design scour depth for a given foundation design. Moreover, Matutano et al. (2013) have compiled a list of different formulae used in the prediction of maximum scour depths which have been derived assuming different flow conditions (current-only, wave-only or combined current and waves). They have highlighted that different standards and recommendations used in the offshore industry suggest different formulations for scour depth estimation, leading to natural variability in design scour depths. In a detailed study, they compared the maximum design scour depths obtained by the implementation of various design formulae with the actual measured scour depths for various wind farm sites around Europe. This analysis revealed that the maximum observed scour depth was less than the estimated value in all but two of the cases considered, which further highlights the uncertainties present in accurate scour depth estimation. Furthermore, Negro et al. (2014) acknowledges the requirement that for effective scour protection design, it is necessary to include sediment properties, geotechnical characteristics of the site, environmental parameters for wave loads and turbine foundation specifications in order to accurately predict the maximum scour that could occur in the absence of such protection. They also call into question the DNV's (Det Norske Veritas, 2013) recommendation for scour characterization around offshore wind turbines under combined current and waves, deeming it to be inaccurate. 
In the absence of adequate scour protection, scour has the effect in design of increasing the cantilever length (or effective water depth) by between the order of 5.2 and $7.8 \mathrm{~m}$ for the piles sizes currently used in practice, under the assumption of current-only induced scour. Scour has the effect of reducing the ultimate capacity of a foundation and reducing the system stiffness (Prendergast and Gavin, 2014). This could, in certain circumstances, lead to the occurrence of resonant vibrations in the structure if the structure's natural system frequency aligns with any of the excitation frequencies from the rotating blades or the passing sea waves. Sørensen and Ibsen (2013) present a desk study investigation on the potential effects of scour on an existing offshore wind farm at Horns Rev 1. Using frequencies obtained from estimates of soil stiffness derived from p-y curves given in the API code, they found that the first natural frequency of a structure reduced by $5 \%$ when the scour depth reached $1.3 \mathrm{D}_{\text {pile. }}$. To counteract the effects of scour, mitigation measures which typically comprise placing rock armour at the sea bed, have been undertaken at a number of sites. These can have the effect of stiffening the foundation response and hence, increasing the system's natural frequency. For a soft-stiff structure, such measures have the potential to cause dynamic load effects with excitation frequencies above the structure's natural frequency.

Recent efforts to measure the natural frequency of offshore structures have revealed that the stiffness of heavily over-consolidated soils may be underestimated when using design values recommended in current design codes (API, 2007; Det Norske Veritas, 2007). For heavy offshore oil and gas platforms, under-estimating the soil stiffness does not have major implications for safety. However when considering light, dynamically sensitive offshore wind turbines it is crucial to accurately predict the structure's system frequency. Even more importantly, it is crucial to demonstrate how changes arising during the lifetime of the structure due to soil stiffness degradation as a result of cyclic loading, or from scour may affect the dynamic response.

This paper presents scale model tests and simple finite element numerical modelling to examine the effects of scour on the natural frequency of a wind turbine supported by a monopile embedded in typical offshore sand deposits. In the first part of the paper, an experiment is performed on a scale model monopile where scour is artificially induced and the change in the natural frequency is measured. The results of this experiment are used to calibrate a numerical model of the soil-pile system developed using simple finite-element methods. In the latter part of the paper, the numerical model was extended to include a full-scale offshore wind turbine founded on a monopile using realistic structural properties corresponding to a 3.6 MW turbine. The numerical model which was developed in MATLAB was used to consider the relative effects of different soil stiffness profiles and scour severity on the system's natural frequency. The potential for accelerometers to be used as a method of monitoring scour on offshore wind turbines is inferred from the results obtained. 


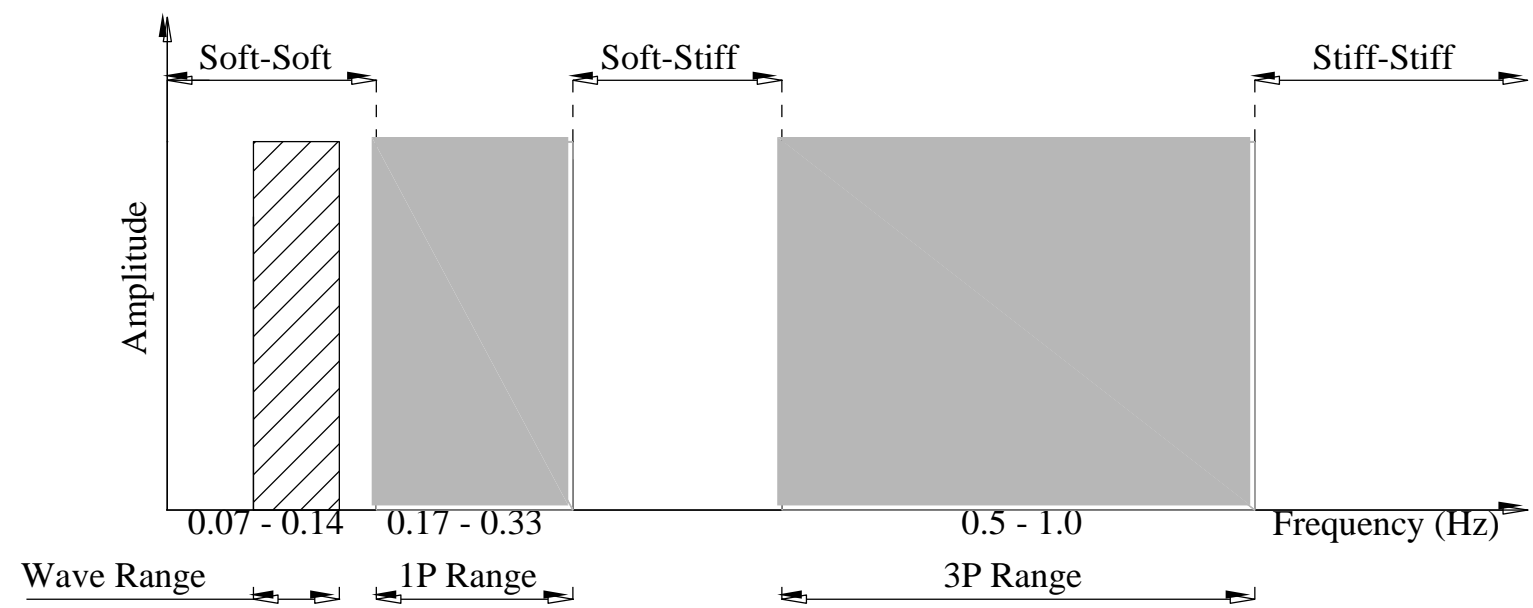

Fig. 1 Excitation frequency ranges for typical offshore wind turbines.

\subsection{Scale-model scour test}

A scale-model experiment was performed by driving a $340 \mathrm{~mm}$ diameter open-ended steel pile to a final penetration depth of $2.2 \mathrm{~m}$ in very dense sand at the University College Dublin (UCD) test site at Blessington, County Wicklow, Ireland. The pile diameter of this experimental monopile is scaled in the range $\approx 1: 12$ to $1: 18$ of those currently used in industry as offshore wind turbine foundations. The embedded depth $\left(\mathrm{L}_{\text {embed }}\right)$ is scaled in the range $\approx 1: 7$ to 1:14 of typical embedment depths for offshore piles (Peder Hyldal Sørensen and Bo Ibsen, 2013). The ratio of embedded depth to pile diameter $\left(\mathrm{L}_{\text {embed }} / \mathrm{D}_{\text {pile }}\right)$ was of the order of 6.5, which is similar to values used in the offshore wind sector.

The test bed is comprised of a very dense, fine sand with a relative density $\left(\mathrm{D}_{\mathrm{r}}\right)$ close to $100 \%$, as determined from sand replacement tests. The mean particle size, $\mathrm{D}_{50}$, varies between $0.1 \mathrm{~mm}$ and 0.15 $\mathrm{mm}$ as determined from particle size distributions analyses undertaken at various depths below ground level (bgl). The specific gravity of the sand particles is 2.69. The maximum and minimum void ratios are 0.73 and 0.37 respectively. The sand has a bulk density of $\approx 2.10 \mathrm{Mg} \mathrm{m}^{-3}$ and a bulk unit weight of $\approx 20 \mathrm{kN} \mathrm{m}^{-3}$. Due to its angularity it has a relatively high constant volume friction angle. Triaxial compression tests undertaken on reconstituted samples of Blessington sand reported in (Tolooiyan and Gavin, 2011) reveal that the sand has a constant volume friction angle $\left(\phi_{c v}^{\prime}\right)$ of $37^{\circ}$ and a peak friction angle $\left(\phi_{p}^{\prime}{ }_{p}\right)$ which varies from $54^{\circ}$ near the ground surface to $42^{\circ}$ at $5 \mathrm{~m}$ below ground level (bgl). Ring shear tests reported in (Doherty et al., 2012) reveal a soil-on-soil average residual friction angle of $36^{\circ}$, which broadly agrees with the values reported above by (Tolooiyan and Gavin, 2011). The sand is partially saturated above the water table with a natural water content of between $10 \%$ and $12 \%$ which does not vary seasonally, and suctions which reduce slightly over the first $2 \mathrm{~m}$ bgl from 12 $\mathrm{kPa}$ to $10 \mathrm{kPa}$. The equilibrium water table is approximately $13 \mathrm{~m}$ bgl. Ten Cone Penetration Test (CPT) tip resistance $\mathrm{q}_{\mathrm{c}}$ profiles were measured at the site with the average and maximum and 
minimum envelopes as shown in Fig. 2(a), which reveal $\mathrm{q}_{\mathrm{c}}$ values that range from 10 to $20 \mathrm{MPa}$ over a depth of $8 \mathrm{~m} \mathrm{bgl}$. The shear wave velocity profile measured using the Multi-Channel Analysis of Surface Waves (MASW) method (Donohue et al., 2004), is shown in Fig. 2(b). Further more detailed descriptions of the test site conditions are available in Igoe et al. (2011) and Doherty et al. (2012). The sand density and bedding conditions at the site are typical of those found in offshore environments.

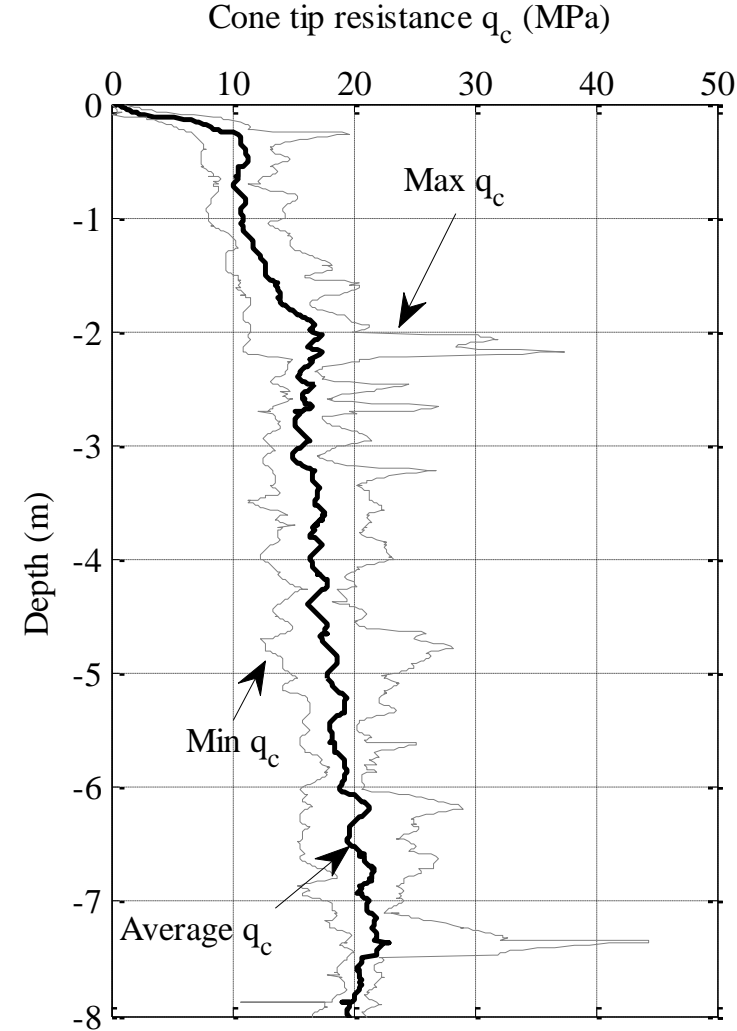

(a)

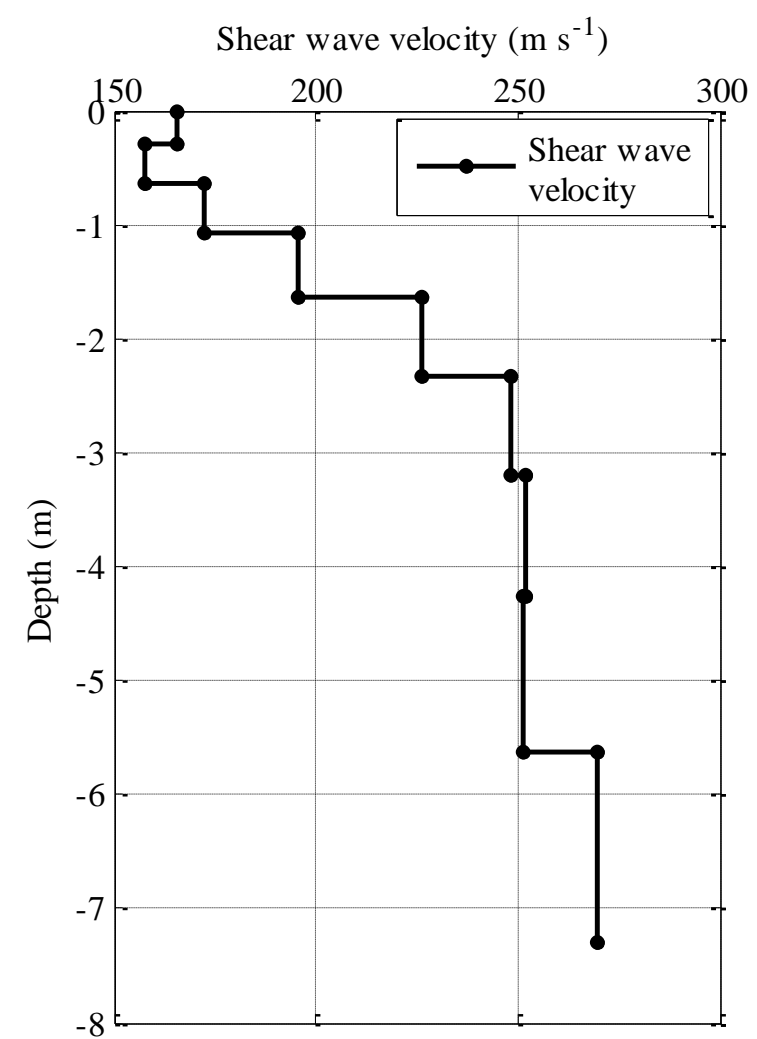

(b)

Fig. 2 Blessington site investigation. (a) Cone tip resistance profile (MPa); (b) Shear wave velocity profile (m s )

The test pile was fitted with accelerometers (see Fig. 3) which were wired into a Campbell Scientific CR9000X datalogger and monitored at a scanning frequency of $1000 \mathrm{~Hz}$. Three accelerometers were fitted before the start of the test, whilst a fourth (the lowest) was added when the scour test had reached a depth of $0.8 \mathrm{~m} \mathrm{bgl}$. A modal hammer was used to produce an initial lateral excitation at the top of the pile. The hammer was calibrated to excite low frequency resonances in the structure (heavy tip mass coupled with a soft impact tip) so the fundamental mode of vibration could be more easily obtained. Scour was then induced in stages by removing $0.2 \mathrm{~m}$ deep soil layers. The impact test was repeated a minimum of five times at each scour depth, with the modal hammer hitting the same location on the pile during each test. In total, nine scour depths were considered, the final scour depth being $1.8 \mathrm{~m}$ or $5.3 \mathrm{D}_{\text {pile }}$ bgl. 


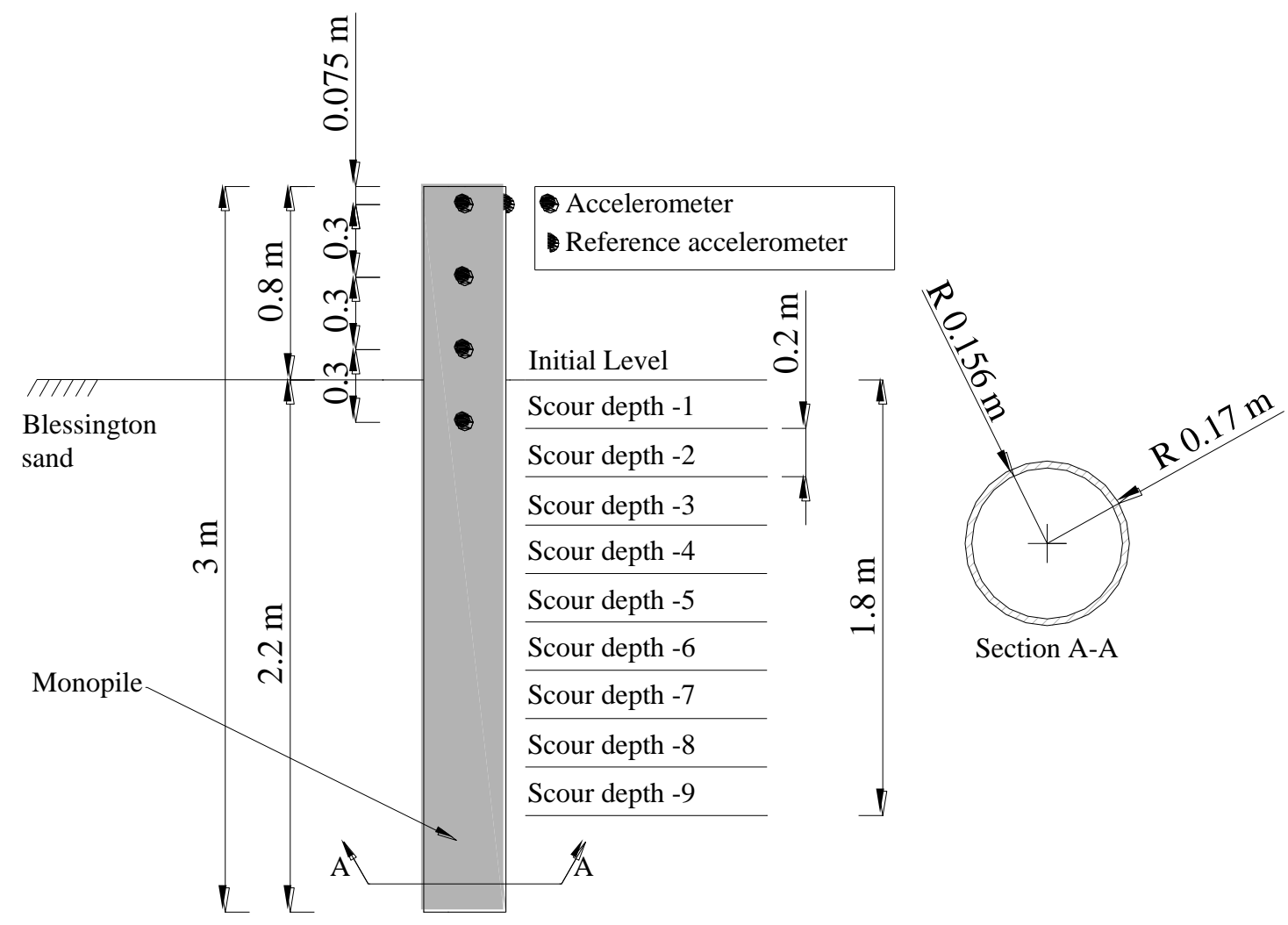

Fig. 3 Test layout schematic (all dimensions in metres).

The frequency response of the structure at each scour level was obtained using two methods. In the first approach, Frequency Response Functions (FRFs) were developed which show the ratio of the measured output to the input stimulus. In this instance, the input stimulus is the time history of the forces applied over the impact duration and the output response is the acceleration measured by each accelerometer. Individual response functions were obtained from each input-output pair to ensure that the frequency obtained by each was in agreement. The second approach used to obtain the frequency response of the structure involved using Frequency Domain Decomposition (FDD), a tool which utilises the signals from all the accelerometers simultaneously to obtain an estimate of the modal properties of the system (Brincker et al., 2001). This procedure is an improvement on the classical Fourier transform approach as it is less sensitive to frequency resolution problems and allows for easier estimation of close modes and damping. In overview, the FDD process involves taking the Singular Value Decomposition (SVD) of the spectral matrix and decomposing it into a set of auto spectral density functions that each correspond to a single degree of freedom (SDOF) system (Brincker et al., 2000). It is generally most effective when the type of input excitation is broad-banded (white noise). In this case, due to the application of an impulse to excite the system, the decomposition into SDOF systems was more approximate (it is exact for white noise excitation and light damping) but the results are still more accurate than those obtained using classical approaches 
(Brincker et al., 2000). For this reason, the FDD results are used in the analysis and the results from the FRFs are used as verification.
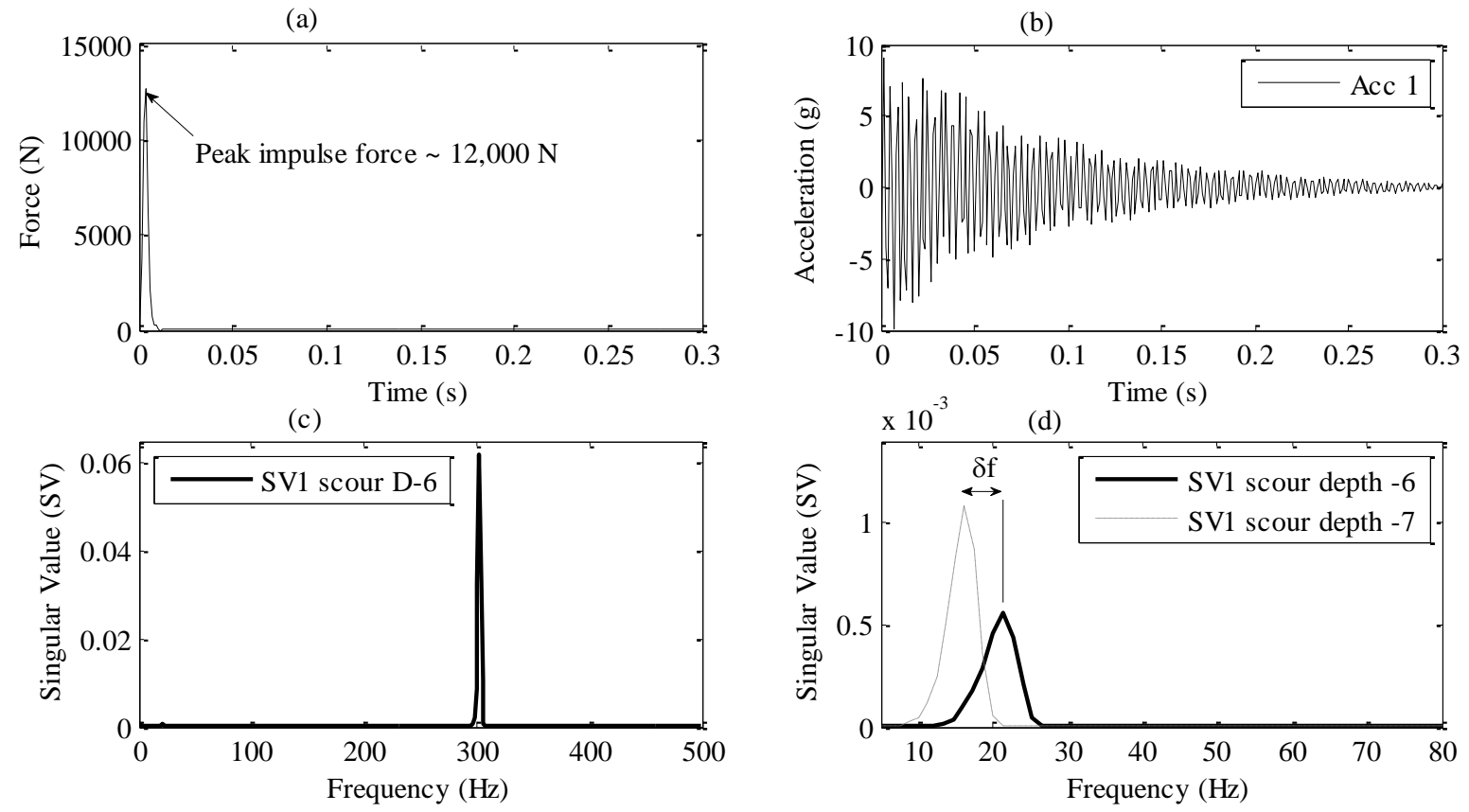

Fig. 4 Experimental results for scour depth -6. (a) Input force time history (N); (b) Output accelerations for scour depth -6; (c) Frequency spectrum from FDD; (d) Isolated first natural frequency for scour depth -6 and scour depth $-7(\mathrm{~Hz})$.

Typical results for scour depth -6 are shown in Fig. 4. Fig. 4(a) shows the input force time history, measured using the modal hammer. Fig. 4(b) shows the acceleration response measured by the top accelerometer arising due to the application of the load shown in Fig. 4(a). In total there are four acceleration signals, however, three are omitted from the figure for clarity. The four acceleration signals are used in the FDD analysis to obtain an estimate of the frequency response of the structure, for the given scour depth. Fig. 4(c) shows the dominant frequency content obtained from the analysis of the four acceleration signals. A dominant peak is seen at approximately $305 \mathrm{~Hz}$, which is too high to be the first natural frequency of the system. In order to isolate the frequency corresponding to the first natural frequency of the structural system, it is necessary to compare the system response to an analytical model. In this case, it is best to obtain an upper-bound frequency threshold by comparing the system response to that of a cantilever, with a free length $\left(\mathrm{L}_{\text {free }}\right)$ equal to the portion of the pile above the ground line (at a given scour depth). The first natural frequency of a cantilever is obtained using the following Eq. (2).

$$
f_{1}=\frac{1}{2 \pi}(1.875)^{2} \sqrt{\frac{E I}{\rho A L_{\text {free }}{ }^{4}}}
$$


where $\mathrm{E}$ is the Young's modulus of the steel $\left(\mathrm{N} \mathrm{m}^{-2}\right)$; I is the moment of inertia of the cross-section $\left(\mathrm{m}^{4}\right) ; \rho$ is the density of the material $\left(\mathrm{kg} \mathrm{m}^{-3}\right)$; $\mathrm{A}$ is the cross-sectional area $\left(\mathrm{m}^{2}\right)$ and $\mathrm{L}_{\text {free }}$ is the free length ( $\mathrm{m})$ above the ground line.

In Fig. 4(d) the frequency content of the spectrum shown in Fig. 4(c) is displayed up to a value of 80 $\mathrm{Hz}$ (the theoretical first natural frequency for a cantilever with a free length corresponding to scour depth -6 is $81.5 \mathrm{~Hz}$ ). From this plot, it can be seen that the measured first natural frequency is 21.3 $\mathrm{Hz}$, for scour depth -6 . The change in first natural frequency between scour depth -6 and scour depth 7 is also shown in this plot. The dominant high frequency peak observed in Fig. 4(c) arises due to localised vibration in the annular cross-section as a result of the application of the impulse load. Similar studies of this phenomenon are reported in (Dezi et al., 2012; Prendergast et al., 2013).

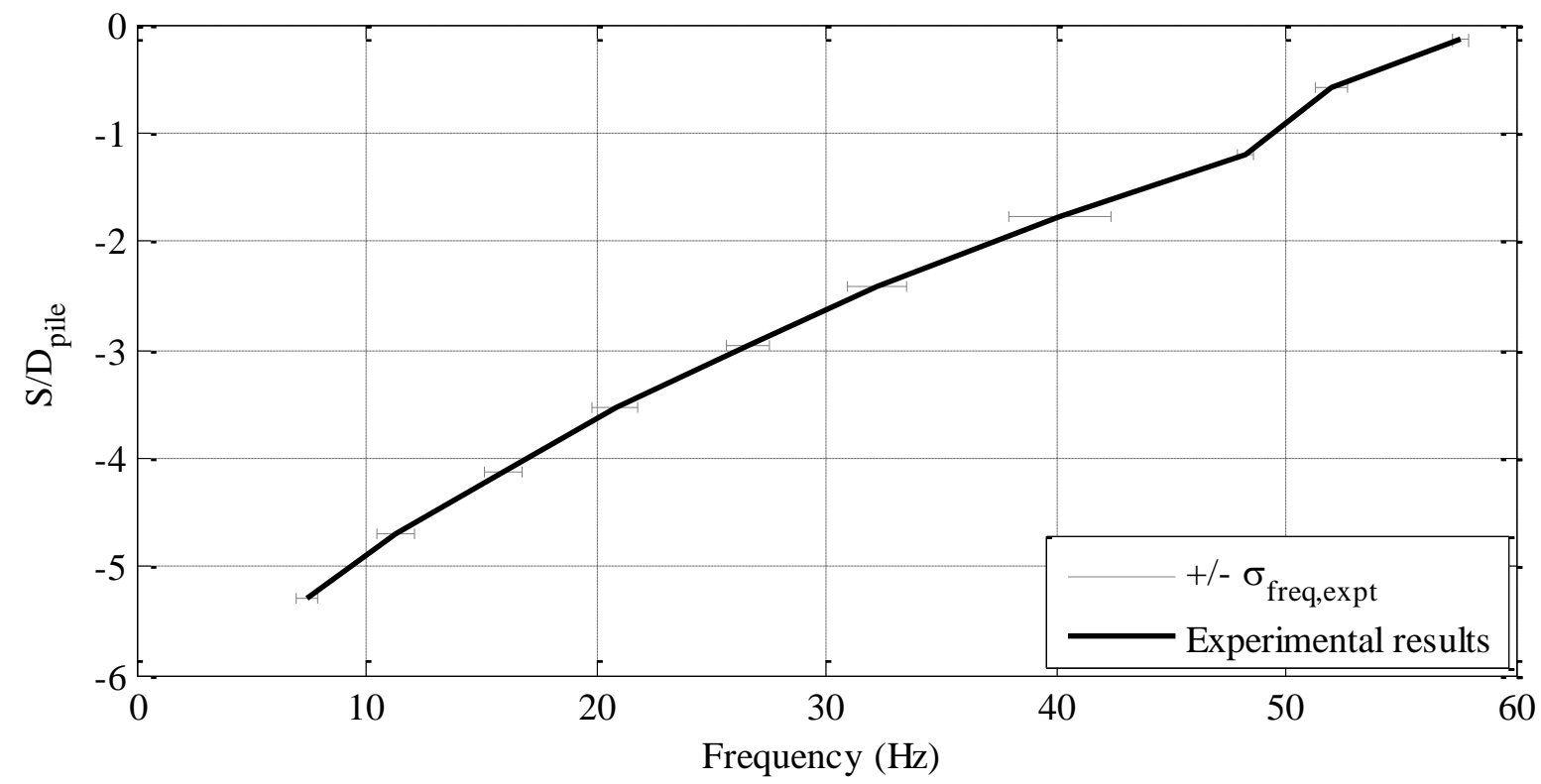

Fig. 5 Frequency change with dimensionless scour depth.

The change in first natural frequency obtained as the scour depth around the pile increased is shown in Fig. 5 for all scour depths tested. The depth of scour is presented in terms of the dimensionless scour depth to pile diameter ratio ( $S / \mathrm{D}_{\text {pile }}$ ). At each scour depth, a number of impacts (minimum of five) were undertaken to ensure repeatability of the results. It is noteworthy that at each scour depth, the frequency was observed to reduce very slightly over the number of impacts, most probably arising as a result of the strain-dependency of soil stiffness with the stiffness reducing due to the repeated application of the heavy modal hammer. As a result, the average values for each scour depth are reported with the standard deviation $\left(\sigma_{\text {freq,expt }}\right)$ shown by the error bars on the plot at each scour depth. It is also noteworthy that for the upper two scour depths, the determination of distinct natural frequency peaks was difficult. This problem arose due to the difficulty in exciting a clear bending vibration mode in the pile due to the high bending stiffness of the pile system when it was close to 
fully embedded. The application of the hammer to the pile for these two scour depths had the effect of predominately exciting the annular vibration, as discussed above, which clouded the frequency spectra adversely. Selection of the most-likely frequency values for the upper two scour depths from the response spectra was aided by following the trend of frequency change with scour starting with the lowest results (see Fig. 4(d) for example of lower scour depth results), which was predominately linear. Therefore, there is some uncertainty in the frequency results presented for the top two depths. From the overall results presented in Fig. 5, however, it is evident that scour has a noticeable effect on the frequency response of this scaled monopile foundation with a reduction in measured frequency of between $\approx 57.6 \mathrm{~Hz}$ for a $S / \mathrm{D}_{\text {pile }}$ of zero to $\approx 7.4 \mathrm{~Hz}$ for a $S / \mathrm{D}_{\text {pile }}$ of 5.3 .

The scale-model test described above was performed in dry sand, i.e. no hydrostatic effects (due to water depth at a turbine location) or excess pore pressures which could develop during cyclic loading, were considered explicitly. In terms of accounting for hydrostatic water pressure in the offshore environment, the actual water depth has no effect on the soil response, i.e. if the saturated unit weight of the soil is constant, then the effective stress at any depth below sea bed level is independent of the water depth. With respect to the potential development of excess pore water pressures during cyclic loading, its effect would be to gradually reduce the effective stress of the soil. The soil strength and stiffness are controlled by the soil's effective stress; therefore any reduction in effective stress will cause a reduction in soil stiffness. Since the natural frequency is directly related to the soil stiffness, in addition to reductions caused by scour, the natural frequency of the structure could reduce as a result of cyclic pore pressure build-up. The development of excess pore pressures will be controlled by the loading frequency, soil permeability, and pile diameter amongst other factors.

\subsection{Numerical modelling of scaled-model test}

A one-dimensional (1-D) finite element numerical model of the soil-structure system was developed in MATLAB to model the effect of scour on the structural vibration response of the experimental monopile. The purpose of this numerical study is to replicate the experimental measurements in the numerical environment such that further sensitivity studies may be performed using realistic properties for a full-scale wind turbine structure.

\subsection{Structural model}

The soil-structure model consists of Euler-Bernoulli beam elements supported by lateral linear springs. The model properties were obtained from the experimental geometries and material properties discussed in section 2.0. The exposed end of the monopile was modelled using standard four degree of freedom (4-DOF) beam elements, with elemental stiffness and mass matrices recommended by Kwon and Bang (2000). The embedded portion of the pile was modelled using modified 5-DOF spring-beam elements. The extra degree of freedom was required to model the lateral 
soil spring. This spring-beam type model, known as the Winkler hypothesis has been shown to provide a reasonable representation of the complex soil-structure interaction problem (Dutta and Roy, 2002). The elements are assembled together into global mass and stiffness matrices. The undamped system natural frequencies and mode shapes are obtained from the model by solving the eigenproblem shown in Eq. (3) (Tedesco et al., 1999).

$$
\llbracket \mathbf{Z}]-\lambda[\mathbf{I}]]\{\mathbf{A}\}=\{\mathbf{0}\}
$$

where $[\mathbf{I}]$ is the Identity matrix and $[[\mathbf{Z}]-\lambda[\mathbf{I}]]$ is a square matrix of order $n$ and is called the characteristic matrix of $[\mathbf{Z}] . \lambda$ is the eigenvalue and $\{\mathbf{A}\}$ is the associated eigenvector. $[\mathbf{Z}]$ is the system matrix formed in Eq. (4).

$$
[\mathbf{Z}]=\left[\mathbf{M}_{\mathbf{G}}\right]^{-1}\left[\mathbf{K}_{\mathbf{G}}\right]
$$

where $\left[\mathbf{M}_{\mathbf{G}}\right]$ and $\left[\mathbf{K}_{\mathbf{G}}\right]$ are the global mass and stiffness matrices for the soil-structure model respectively, and include the contribution from the soil springs in the model. The eigenvalues and eignevectors of $[\mathbf{Z}]$ can be obtained as the roots of the characteristic equation, obtained by expansion of Eq. (5).

$$
\|[\mathbf{Z}]-\lambda[\mathbf{I}]=0
$$

The system matrix $[\mathbf{Z}]$ was specified in MATLAB for the soil-structure system and the eigenvalues and eigenvectors (natural frequencies and mode shapes) were obtained using in-built functions available in the MATLAB programming environment.

Scour was modelled as the removal of springs from the numerical model. An eigenvalue analysis was undertaken for each spring removal phase and a profile of frequency against scour was generated. The numerical model of the soil-structure system is shown schematically in Fig. 6. 


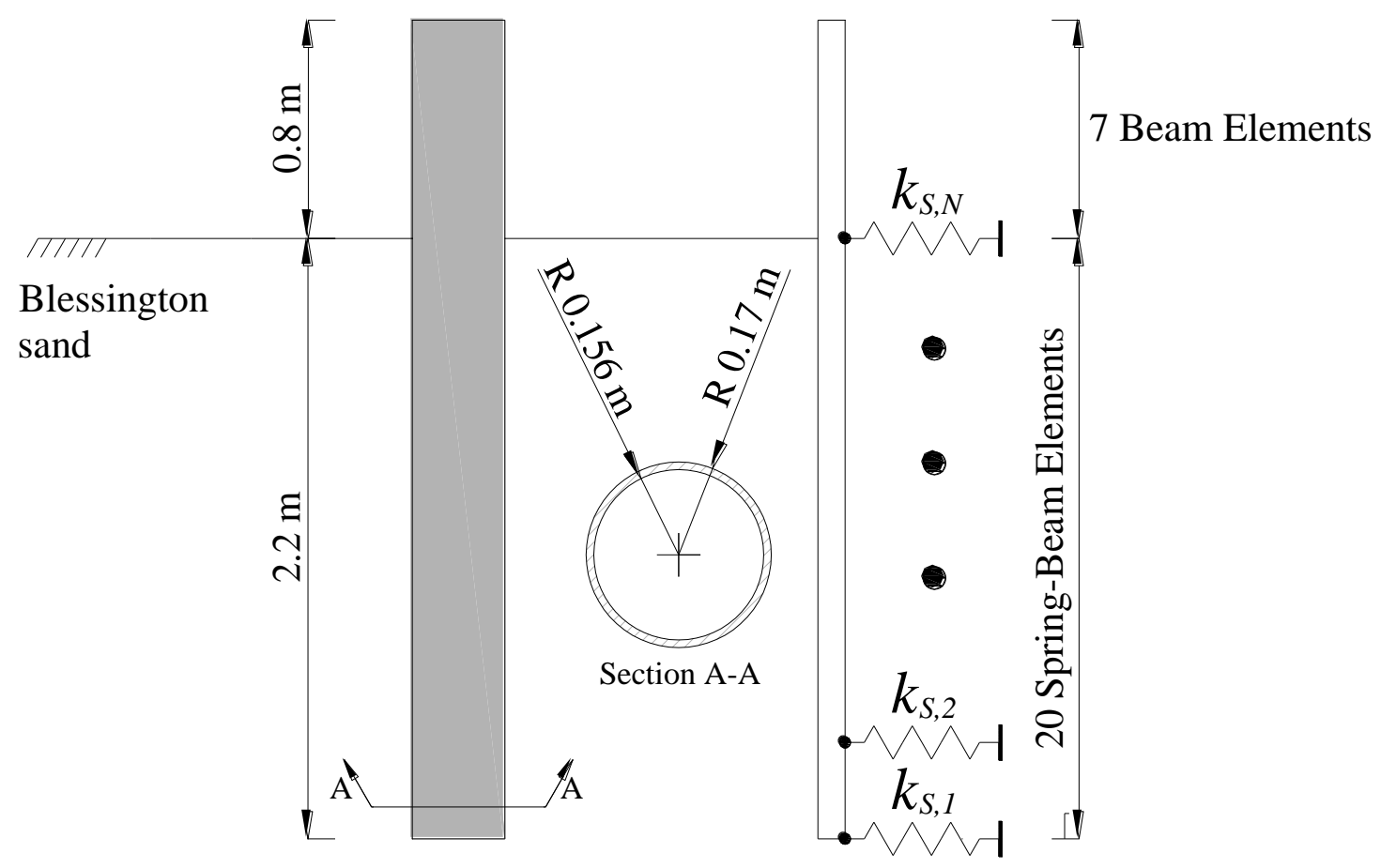

Fig. 6 Schematic of numerical model of soil-structure system.

\subsection{Sand spring stiffness}

In the numerical modelling of this problem, the largest uncertainty with respect to input parameters relates to the spring stiffness coefficients that are used to model the in-situ soil stiffness. In spite of the slight deviation in observed frequency at each scour depth due to the repeated application of the impact load, it can generally be assumed that the dynamic loading applied to establish the natural frequency of the structure induced very small displacements. Therefore, the small-strain stiffness of the soil can be used as a fair approximation to model soil displacements. Shear wave velocity $\left(\mathrm{v}_{\mathrm{s}}\right)$ measurements can be used to determine the small-strain shear modulus, $\mathrm{G}_{0}$, of the soil if the soil density $\rho$ is known (Eq. (6)).

$$
G_{0}=\rho v_{s}^{2}
$$

For sites where $\mathrm{v}_{\mathrm{s}}$ data is not available correlations with CPT $\mathrm{q}_{\mathrm{c}}$ values are commonly adopted in practice (Schnaid et al., 2004). The ratio $\mathrm{G}_{0} / \mathrm{q}_{\mathrm{c}}$, known as the rigidity index is known to depend on soil density, current stress level and loading history, degree of cementation and age of the deposit amongst other factors (Fahey et al., 2003; Robertson, 1997). For the aged, over-consolidated sand at the Blessington test site where the experiment was performed, a $\mathrm{G}_{0} / \mathrm{q}_{\mathrm{c}}$ ratio in the range 5 to 8 would be expected. A ratio of 6 , which was adopted in the analysis described herein, was seen to provide a reasonable estimate of the small-strain shear modulus inferred from the MASW measurements of shear wave velocity at the site (see Fig. 7). 
The derived $G_{0}$ profiles were used to form discrete spring stiffness coefficients $\left(\mathrm{k}_{\mathrm{s}}\right)$ for use in the dynamic analysis in the 1-D finite element model. In the first instance, the shear modulus profile was converted to an equivalent Young's modulus $\left(\mathrm{E}_{0}\right)$ profile using an appropriate small-strain Poisson's ratio $(v=0.1)$ using Eq. (7).

$$
E_{0}=2 G_{0}(1+v)
$$

The material properties of the soil and pile are coupled using Eq. (8). This expression allows a profile of the modulus of subgrade reaction $(\mathrm{K})$ to be determined for the solution to the problem relating to a beam on an elastic foundation (Ashford and Juirnarongrit, 2003).

$$
K=\frac{1.0 E_{0}}{1-v^{2}}\left[\frac{E_{0} D^{4}}{E_{p} I_{p}}\right]^{1 / 12}
$$

where $E_{p}$ is the Young's modulus of steel $\left(\mathrm{N} \mathrm{m}^{-2}\right)$ and $I_{p}$ is the moment of inertia of the cross-section $\left(\mathrm{m}^{4}\right)$. The $\mathrm{G}_{0}$ values derived from both the shear wave velocity and CPT measurements used in the analysis are shown in Fig. 7 over the depth of embedment of the experimental monopile.

A total of 20 springs spaced at $0.111 \mathrm{~m}$ intervals was used to model the initial un-scoured state as shown in Fig. 6. Individual spring coefficients $\left(\mathrm{k}_{\mathrm{s}}\right)$ are calculated by multiplying the $\mathrm{K}$ value at a given spring depth by the spacing between subsequent springs $(x)$ at that depth. Scour is modelled by sequentially removing springs from the model, corresponding to a loss in soil support, and performing an eigenvalue analysis at each depth to obtain the natural frequencies of the system. 


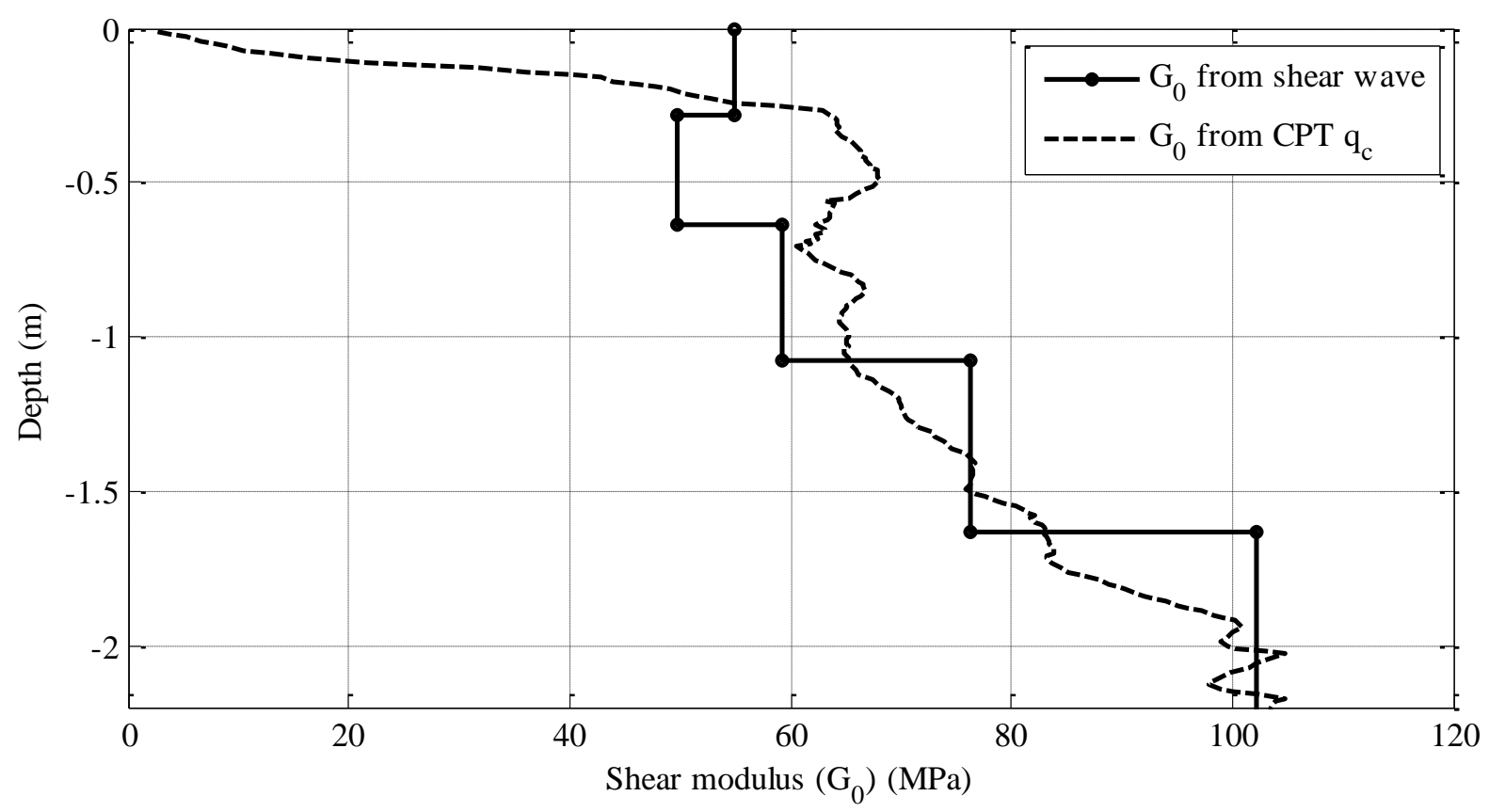

Fig. 7 Profile of shear modulus $\left(\mathrm{G}_{0}\right)$ developed using $\mathrm{v}_{\mathrm{s}}$ measurements and CPT $\mathrm{q}_{\mathrm{c}}$ data.

\subsection{Results of experimental and numerical modelling of scaled-model test}

The frequency values for a range of scour depths were obtained as the eigenvalues of the system matrix after removal of each spring used to simulate scour (see Fig. 6). The results of the numerical analyses for all scour depths using $\mathrm{G}_{0}$ values derived from both shear wave velocity measurements and CPT $\mathrm{q}_{\mathrm{c}}$ values are compared to the measured experimental response in Fig. 8. This figure shows the change in natural frequency of the monopile due to progressive scour with the numerical predictions also shown, plotted against the dimensionless $S / D_{\text {pile. }}$. 


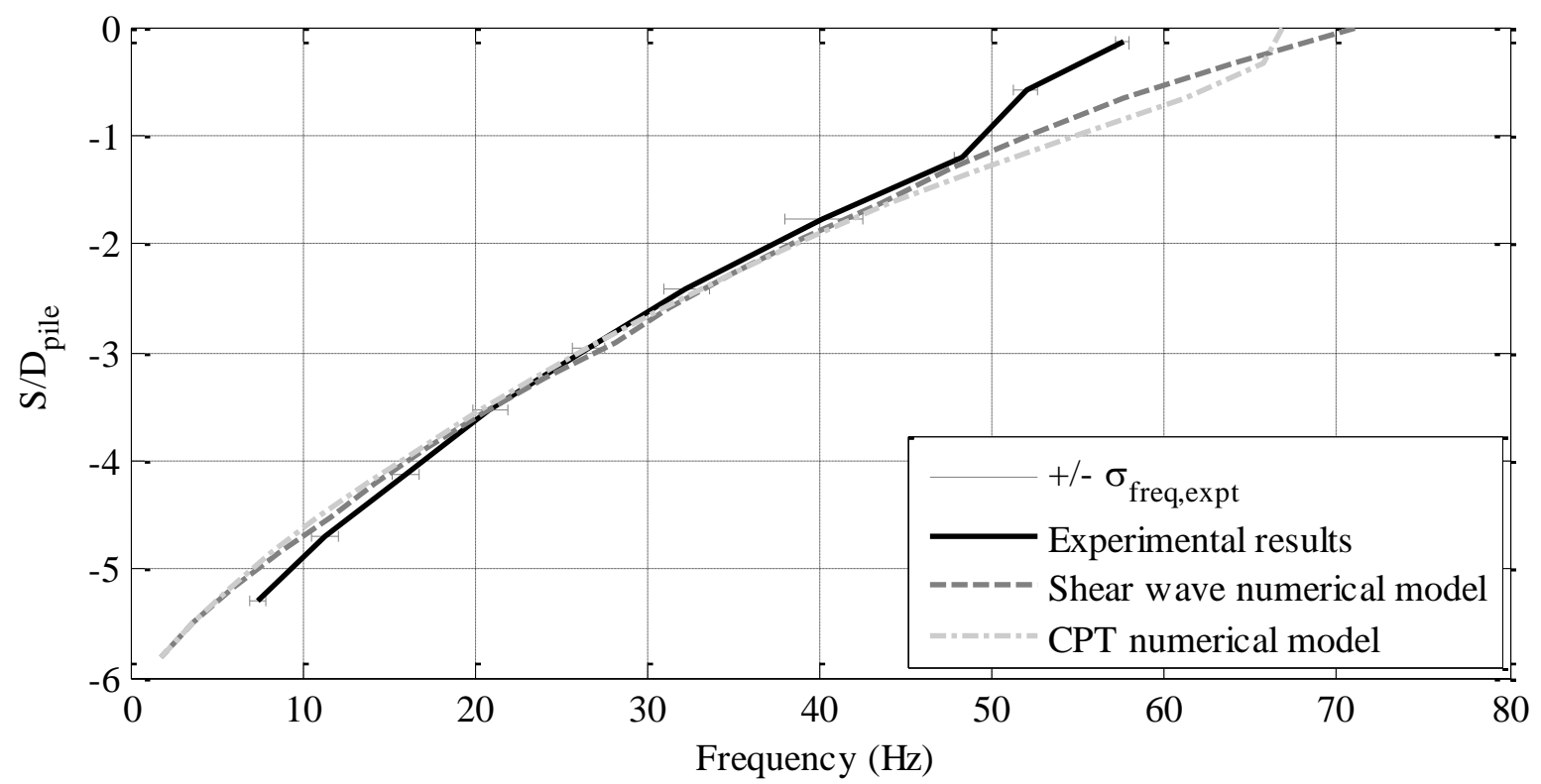

Fig. 8 Results of numerical and experimental investigation - frequency change with scour.

From the results shown in Fig. 8, it is clear that the model provides a good match to the measured experimental response using both the shear wave velocity and CPT data to estimate the soil spring stiffness. It is worth noting that the experimental response at the uppermost scour depths deviates away from the numerical predictions. As was stated in section 2.0, there was a degree of uncertainty associated with obtaining a clear frequency peak for these depths. This uncertainty arose due to the difficulty in inducing a clear bending vibration mode with the impact hammer as a result of the high system stiffness when the pile was fully embedded. Overall however, the results are satisfactory and moreover, they indicate that once a reasonable estimate of $\mathrm{G}_{0}$ can be made, the simple 1-D model presented can be used to quantify the effect of scour on the natural frequency of a scaled monopile system.

In practice, the presence of a structure, e.g. a wind turbine tower, nacelle etc., will have a significant influence on the frequency response of the system. In section 5.0, a turbine-foundation numerical model is developed to explore this interaction.

\subsection{Design example - wind turbine model}

A numerical model of a full-scale offshore wind turbine was developed using MATLAB by employing the same spring-beam modelling philosophy as outlined in section 3.1. In addition to considering scale effects, the purpose of this model was to include the structural mass, realistic loads and to investigate the effect of sand density or initial stiffness on the frequency change induced by scour. The wind turbine model consisted of a nacelle supported on an annular tower, which was founded on a monopile embedded in sand. The turbine was founded on a $6 \mathrm{~m}$ diameter monopile with 
a wall thickness of $90 \mathrm{~mm}$ embedded $30 \mathrm{~m}$ into sand (see Fig. 9). Details of the model properties are outlined in Table 1.

Table 1 Offshore wind turbine properties.

\begin{tabular}{|c|c|c|c|}
\hline Tower Properties: & Value: & Monopile Properties: & Value: \\
\hline Tower length (m) & 70 & Monopile length (m) & 75 \\
\hline Material & Steel & Embedded length (m) & 30 \\
\hline Density $\left(\mathrm{kg} \mathrm{m}^{-3}\right)$ & 7850 & Material & Steel \\
\hline $\begin{array}{l}\text { Young's modulus } \\
\text { (MPa) }\end{array}$ & 210,000 & Density $\left(\mathrm{kg} \mathrm{m}^{-3}\right)$ & 7850 \\
\hline Tower diameter (m) & $5-3.5$ & $\begin{array}{l}\text { Young's modulus } \\
(\mathrm{MPa})\end{array}$ & 200,000 \\
\hline $\begin{array}{l}\text { Tower wall thickness } \\
\text { (m) }\end{array}$ & 0.045 & Monopile diameter (m) & 6 \\
\hline $\begin{array}{l}\text { X-sectional area }\left(A_{i t}\right) \\
\left(\mathrm{m}^{2}\right)\end{array}$ & $0.7005-0.4884$ & $\begin{array}{l}\text { Monopile wall } \\
\text { thickness (m) }\end{array}$ & 0.09 \\
\hline $\begin{array}{l}\text { Moment of inertia }\left(I_{i t}\right) \\
\left(\mathrm{m}^{4}\right)\end{array}$ & $2.15-0.7289$ & $\begin{array}{l}\text { X-sectional area }\left(A_{m}\right) \\
\left(\mathrm{m}^{2}\right)\end{array}$ & 1.67 \\
\hline $\begin{array}{l}\text { Nacelle mass }\left(\mathrm{M}_{\mathrm{Top}}\right) \\
(\mathrm{kg})\end{array}$ & 230,000 & $\begin{array}{l}\text { Moment of inertia }\left(I_{m}\right) \\
\left(\mathrm{m}^{4}\right)\end{array}$ & 7.2974 \\
\hline $\begin{array}{l}\text { Nacelle rotational } \\
\text { inertia transverse } \\
\text { direction }(J)\left(\mathrm{kg} \mathrm{m}^{2}\right)\end{array}$ & $2.21 \times 10^{7}$ & $\begin{array}{l}\text { Mass of power unit at } \\
\text { interface level } \\
\left(\mathrm{M}_{\text {Transition }}\right)(\mathrm{kg})\end{array}$ & 27,000 \\
\hline $\begin{array}{l}\text { Nacelle rotational } \\
\text { inertia fore-aft } \\
\text { direction }(J)\left(\mathrm{kg} \mathrm{m}^{2}\right)\end{array}$ & $3.5 \times 10^{7}$ & & \\
\hline
\end{tabular}

The tower was modelled using 140 standard Euler-Bernoulli 4-DOF beam elements $\left(\mathrm{N}_{\text {tower }}\right)$, each element being $0.5 \mathrm{~m}$ in length giving a total tower height of $70 \mathrm{~m}$. The monopile was modelled using a total of 150 elements $\left(\mathrm{N}_{\text {pile }}\right)$, giving a total monopile length of $75 \mathrm{~m}$. Of these 150 monopile elements, the embedded portion was modelled using modified 5-DOF ( $\left.\mathrm{N}_{\text {springs }}\right)$ elements to account for the extra DOF associated with the soil spring. The remaining $\mathrm{N}_{\text {pile }}-\mathrm{N}_{\text {springs }}$ elements were modelled using standard 4-DOF beam elements, similar to the tower, to model the exposed portion of the 
monopile. The embedded portion of the monopile was initially modelled using a total of $60 \mathrm{~N}_{\text {springs }}$ elements, to model the un-scoured state, giving an initial embedded depth of $30 \mathrm{~m}$. A water depth of $30 \mathrm{~m}$ was included in the model. This water depth is in the approximate range of depths where monopile foundations are typically used (Peder Hyldal Sørensen and Bo Ibsen, 2013). The effect of the water depth is to increase the cantilevered length of the monopile. No fluid-structure interaction was modelled between the monopile and the surrounding water, although it is recognised that the presence of water may alter the dynamic response. The nacelle was modelled as a lumped mass at the top node of the tower $\left(\mathrm{M}_{\text {Top }}\right)$ with a rotational inertia $(J)$ as specified in Table 1 and includes the contribution from the mass of the rotor and the blades. The discretized modelling approach can give a very good approximation of the natural frequencies of the system and removes the need for more computationally intensive finite element analysis of the continuous system (Murtagh et al., 2004). The gyroscopic effect of blade rotation on the frequency of the turbine was not modelled. The transition piece between the monopile and the tower was modelled as a lumped mass applied to the top node of the monopile $\left(\mathrm{M}_{\text {Transition }}\right)$. A fixed connection was considered between the turbine tower and the monopile. In total, 290 elements were used to define the model from the base of the monopile to the lumped mass at the tower top, each $0.5 \mathrm{~m}$ in length.

In order to check for model compliance, the model was fixed at the tower base and the natural frequencies obtained for a range of tower diameters and thicknesses were compared to the following approximation for a beam with a mass at its tip shown in Eq. (9), (Tempel and Molenaar, 2002).

$$
f_{1} \cong\left[\frac{3.04}{4 \pi^{2}} \frac{E I}{\left(M+0.227 \mu L_{\text {free }}\right) L_{\text {free }}{ }^{3}}\right]^{\frac{1}{2}}
$$

where $\mu=$ tower mass per metre $\left(\mathrm{kg} \mathrm{m}^{-1}\right), \mathrm{M}=$ tip mass $(\mathrm{kg})$ and $\mathrm{L}_{\text {free }}$ is the free cantilevered length (m). Excellent agreement between the clamped numerical model and the approximations from Eq. 9 were observed, with deviations typically being of the order of $1 \%$. 


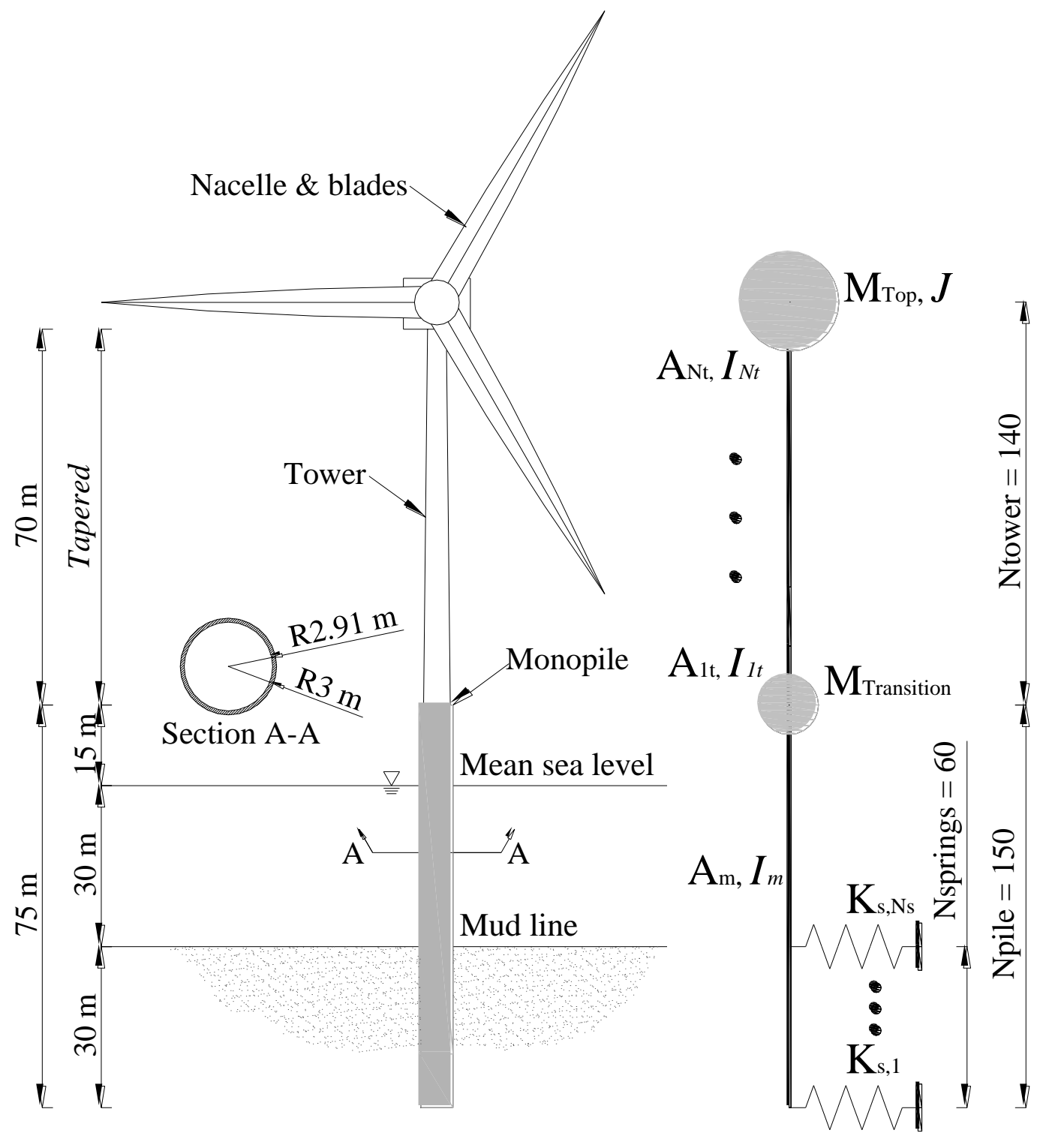

Fig. 9 Wind turbine model and numerical schematic.

Soil stiffness coefficients were assigned using soil classifications based on the American Petroleum Institute design code (API, 2007), which describes sand behaviour based on relative density $\left(D_{r}\right)$. To consider the range of sands typically encountered in the offshore environment, uniform soil deposits 30 m deep with $\mathrm{D}_{\mathrm{r}}$ values of $30 \%, 50 \%$ and $80 \%$ were considered. Synthetic CPT profiles (see Fig. 10) were derived using Eq. (10) (Lunne and Christopherson, 1983).

$$
D_{r}=\frac{1}{2.91} \ln \left\{\frac{q_{c}}{\left[60\left(\sigma_{v}^{\prime}\right)^{0.7}\right]}\right\}
$$

which can be rearranged to give: 


$$
q_{c}=60\left(\sigma_{v}^{\prime}\right)^{0.7} \exp \left(2.91 D_{r}\right)
$$

where $\sigma_{v}^{\prime}$ is the vertical effective stress $(\mathrm{kPa})$. The vertical effective stress was calculated by assuming bulk unit weights of 16,18 and $20 \mathrm{kN} \mathrm{m}^{-3}$, corresponding to loose, medium dense and very dense sand and a bulk unit weight of water $\left(\gamma_{\mathrm{w}}\right)$ of $10 \mathrm{kN} \mathrm{m}^{-3} . \mathrm{G}_{0}$ profiles were derived from the CPT $\mathrm{q}_{\mathrm{c}}$ values using Eq. (11) (Jardine et al., 2005).

$$
G_{0}=q_{c}\left[A+B \eta-C \eta^{2}\right]^{-1}
$$

where $\mathrm{A}=0.0203 ; \mathrm{B}=0.00125 ; \mathrm{C}=1.216 \mathrm{E}-6$ and $\eta=q_{c}\left(P_{a} \sigma^{\prime}{ }^{\prime}\right)^{-0.5} . \mathrm{P}_{\mathrm{a}}=100 \mathrm{kPa}, \sigma^{\prime}{ }_{v 0}=$ vertical effective stress $(\mathrm{kPa})$. The resultant $\mathrm{G}_{0} / \mathrm{q}_{\mathrm{c}}$ values for the soil profiles assumed ranged from 14-23 for loose sand to 4-8 for dense sand profiles.

(a)

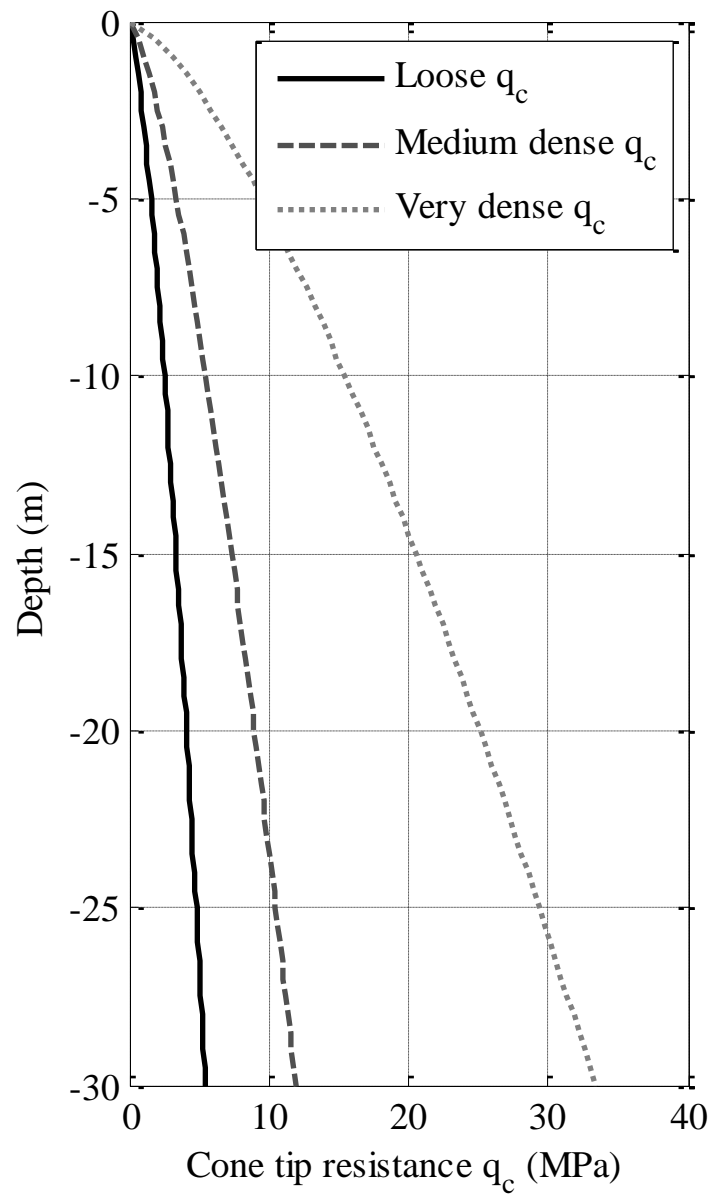

(b)

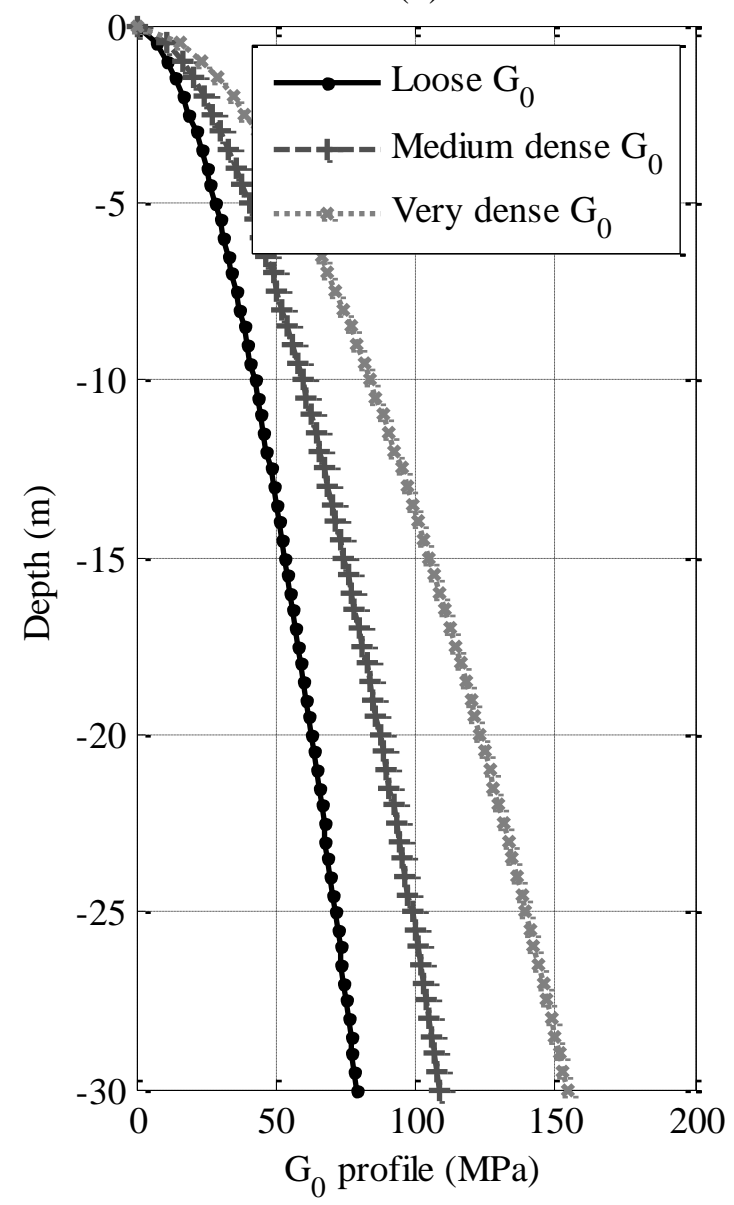

Fig. 10 Synthetic site profiles. (a) Generated $\mathrm{q}_{\mathrm{c}}$ profiles; (b) Generated $\mathrm{G}_{0}$ profiles for loose, medium dense and very dense sand deposits. 
In order to investigate the potential changes in natural frequency of the turbine structure arising due to scour, a reasonable estimate of a design scour depth is required in the first instance. In this particular example, the current-only design value of $1.3 \mathrm{D}_{\text {pile }}$ is considered. Since scour depth is generally small when waves are dominating and large when currents are dominating (Peder Hyldal Sørensen and Bo Ibsen, 2013), the current-only design value is a reasonable datum for potential extreme scour affecting the offshore turbine. The results of the analyses on the full turbine model are shown in Fig. 11(a), with scour being induced up to and beyond the current-only design scour depth of $1.3 \mathrm{D}_{\text {pile. This figure }}$ shows the change in natural frequency of the full turbine structure plotted against the dimensionless scour depth ratio $\left(S / D_{\text {pile }}\right)$ for all three soil stiffness estimates. For a monopile with no scour, the natural frequency of the full system varied from $0.2913 \mathrm{~Hz}$ in loose sand, to $0.3056 \mathrm{~Hz}$ in very dense sand. This can be compared to a $1 \mathrm{P}$ frequency of $0.22 \mathrm{~Hz}$ for a typical 3.6 MW turbine and a 3P frequency of $0.66 \mathrm{~Hz}$. The structure is safely within the soft-stiff range. As scour proceeded beyond $1.3 \mathrm{D}_{\text {pile }}$ to $1.66 \mathrm{D}_{\text {pile }}$, or an absolute scour depth of $10 \mathrm{~m}$, the natural frequency of the structure reduced to $0.2548 \mathrm{~Hz}$ for the loose sand and $0.2771 \mathrm{~Hz}$ for very dense sand, i.e. safely above the $1 \mathrm{P}$ frequency level. The rate at which the frequency reduced with scour for different soil densities is considered in Fig. 11(b). This shows that during the initial stages of scour ( $\mathrm{S} / \mathrm{D}_{\text {pile }}$ values up to 0.5 or absolute scour depths up to $3 \mathrm{~m}$ ), the soil density has very little effect on the dynamic response. However, for scour depth ratios between 0.5 and 1.66 (absolute scour depths between $3 \mathrm{~m}$ and $10 \mathrm{~m}$ ), the loose sand model exhibited relatively greater reductions in natural frequency than the medium-dense or very dense sand models with a maximum reduction of $\approx 12.5 \%$ at $\mathrm{S} / \mathrm{D}_{\text {pile }}=1.66(\mathrm{~S}=10 \mathrm{~m})$ or $\approx 8.5 \%$ at the design scour depth ratio of $1.3(\mathrm{~S}=7.8 \mathrm{~m})$. This is larger than the differences reported from studies. Sørensen and Ibsen (2013) reported relative reductions of approximately 5\% for scour over $1.3 \mathrm{D}_{\text {pile }}$. However, in their study, the authors adopted the API recommended stiffness profiles for sand which increase linearly with depth. The $\mathrm{G}_{0}$ profiles adopted in the present study (see Fig. 10(b)) are arguably more realistic for offshore soil conditions showing stiffness's for a given sand density which vary non-linearly with the mean stress level. The result of this is that the soil stiffness near the sea bed level is relatively higher, and as a result, the loss of material due to scour has a more significant effect on the frequency response of the turbine using the soil profiles adopted in this paper. 

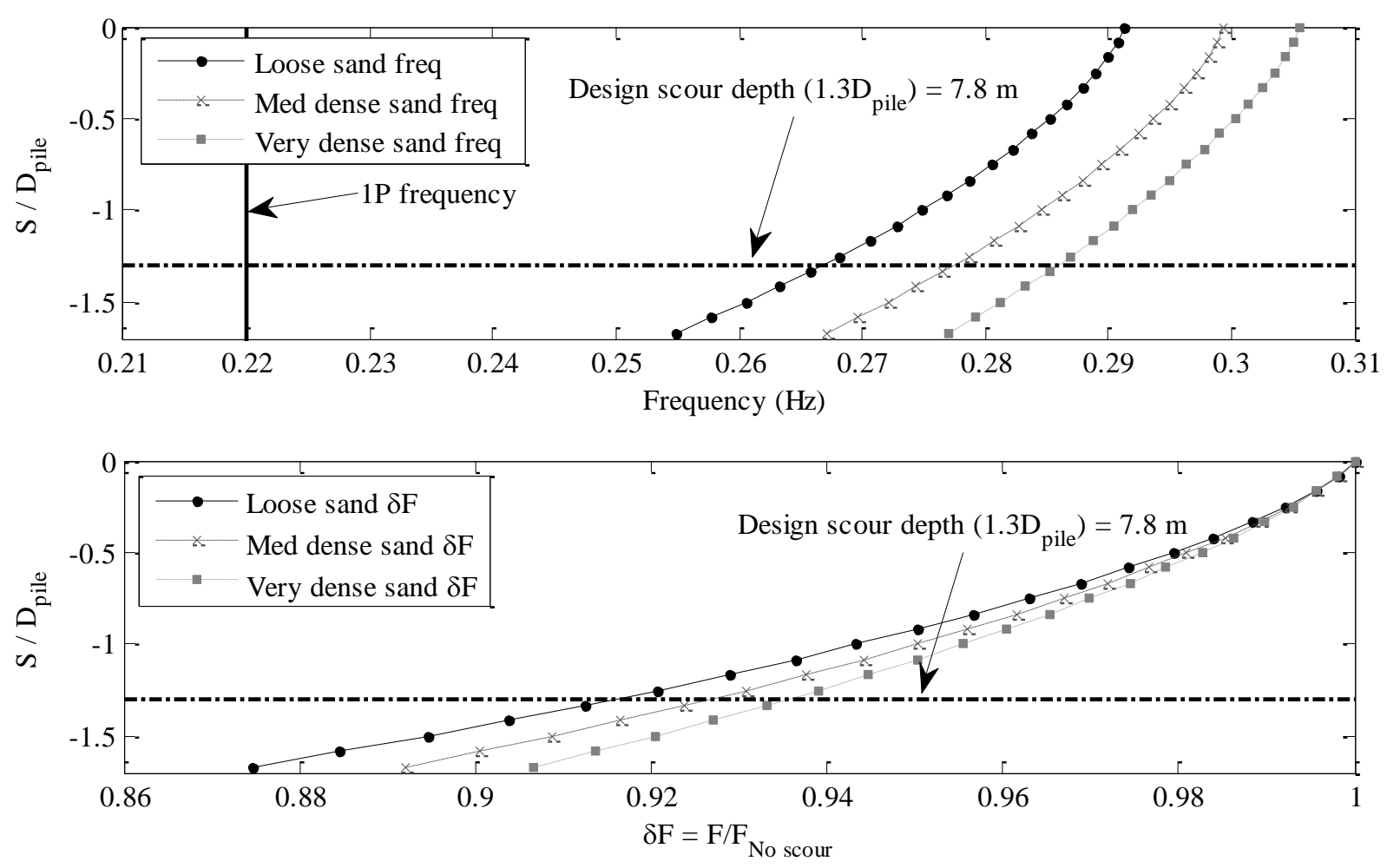

Fig. 11 Effect of scour on the system frequency of an offshore wind turbine. (a) Effect of scour with loose, medium dense and very dense sand profiles; (b) Relative effect of scour using each stiffness profile.

In the analysis described above, continuous scour was assumed to occur over the full design depth and beyond without any backfilling. In reality, scour will be time-dependant, with the action of currents and waves creating oscillations in the equilibrium scour depth and will typically be less than the current-only design value presented above with the action of waves generally leading to a lower local scour depth. By assuming constant removal of material, the system frequency can be observed to drop significantly as the support due to the soil is removed. It is noteworthy that when backfilling occurs, the stiffness of the in-fill material may be similar to that of the removed material. One experiment undertaken by Sørensen et al. (2010) measured the relative density of backfilled material to be 65$80 \%$, which corresponds to dense sand. However, the relative density was only determined for one backfill experiment so further research would be required to make a definitive conclusion in this regard. Also, the fact that there will be a lag in time between the scouring and backfilling process means that for a given period of time, the natural frequency of the structure may be significantly reduced. Waves compacting sediment near the mudline can lead to high relative density in sub-surface sands, therefore it can be expected that backfilled material may become more dense with time (Augustesen et al., 2009). This means that the natural frequency of the wind turbine structure could vary considerably as scour and backfilling occurs. It is also noteworthy that, in many cases, the actual scour depth occurring around a turbine foundation at a wind farm site may be less than the design value so there is still some uncertainty present in the prediction of an equilibrium scour depth (Matutano et al., 2013). 
The change in mode shape exhibited by the full wind turbine structure for the loose sand case is shown in Fig. 12. The mode shapes were derived from the eigenvectors of the system as discussed in section 3.1. Fig. 12(a) shows the first mode shape for the structure founded in the loose sand deposit prior to scouring. Fig. 12(b) shows the un-scoured mode shape in black with dashed line style and the scoured mode shape in grey with solid line style. The scour depth shown corresponds to the currentonly design scour depth of $1.3 \mathrm{D}_{\text {pile, }}$, which in this case is $7.8 \mathrm{~m}$ absolute scour. The results for the medium dense and very dense sand are not shown but they exhibit a similar mode shape for the change in soil support level. This figure provides a visualisation of the effect of scour on the natural frequency response of the wind turbine structure.

On a real full-scale monopile foundation in the offshore environment, the scour process takes place under water therefore it is important to acknowledge the potential effect that the presence of water around the pile could have on the natural frequency of the system. In the case of using accelerometers to detect and monitor scour via changes in frequency, it is imperative to establish whether the presence of water would have any significant effect on the perceived stiffness of the system. A laboratory investigation performed by Prendergast et al. (2013) aimed to highlight the changes in measured natural frequency of vibration between cantilever structures of varying cross-sectional stiffness vibrating in air and immersed in water. Three different cantilever structures, with ratios of flexural rigidity to free cantilevered length $\left(\mathrm{EI} / \mathrm{L}_{\text {free }}\right)$ values ranging from $3.63 \mathrm{E}+02 \mathrm{~N} \mathrm{~m}$ to $6.64 \mathrm{E}+05$ $\mathrm{N}$ m were tested. The research concluded that the stiff structure (highest $\mathrm{EI} / \mathrm{L}_{\text {free }}$ value) seemed to exhibit relatively little change in measured natural frequency between air and water compared to the flexible structure (lowest EI/L $\mathrm{L}_{\text {free}}$ ), which showed more sensitivity to the presence of water. With regard to the current analysis, by taking a conservative $L_{\text {free }}$ value of $75 \mathrm{~m}$ equal to the full length of the numerical monopile, this gives a $\mathrm{EI} / \mathrm{L}_{\text {free }}$ value of $1.95 \mathrm{E}+10 \mathrm{~N} \mathrm{~m}$, which is several orders of magnitude higher than the stiffest experimental section tested by (Prendergast et al., 2013). In reality, due to the partial embedment of the pile, the $\mathrm{L}_{\text {free }}$ value will be lower leading to an even higher $\mathrm{EI} / \mathrm{L}_{\text {free }}$ value than that reported here. Therefore, it is assumed that the water-added mass effect will be negligible for stiff monopiles. It must be noted, however, that there is still some uncertainty with regard to the water-added mass effect on structures and this is an area of ongoing research (Sedlar et al., 2011). Due to the difficulty in quantifying water-added mass and the numerical complexity involved (Ju, 2013), its effect on the natural frequency of vibration has been ignored in the present study.

The dynamic movements estimated from the analysis presented above have a total range of $0.3056 \mathrm{~Hz}$ in the un-scoured dense sand deposit to $0.2548 \mathrm{~Hz}$ in the scoured loose sand deposit, which indicates a relatively slow cyclic loading rate at the soil-pile interface. Since the analysis presented here pertains to sand deposits, drained conditions are assumed to govern the soil-structure interaction (Chow, 1997; Gavin et al., 2013; Lehane, 1992). Therefore, the potential for the build-up of pore pressures in the 
soil as a result of cyclic loading is ignored in the present study. However, it is noteworthy that this is an area of ongoing uncertainty and may not be a true representation of the actual complex soilstructure interaction (LeBlanc et al., 2010). It should be noted that the potential build-up of pore pressures would lead to a gradual reduction in the soil's effective stress, and moreover since the soil strength and stiffness are controlled by this effective stress, a reduction in soil stiffness could occur. This, in tandem with the scour effect, could further lower the natural frequency of the system. Further studies are required to quantify potential pore water effects that have not been considered here.
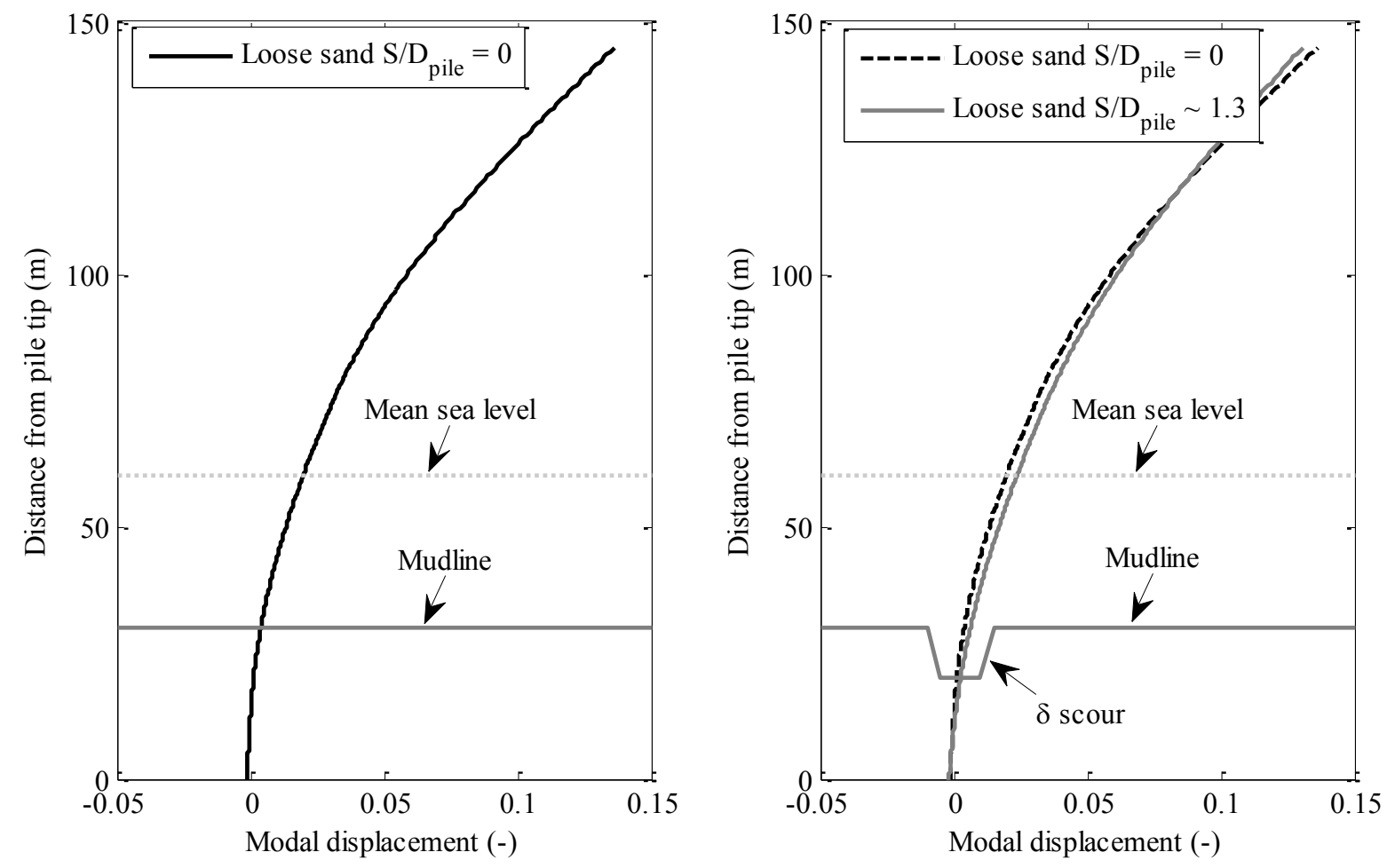

Fig. 12 Change in mode shape in loose sand stiffness profile over design scour ratio of 1.3 for full structure.

\subsection{Conclusions}

An experimental programme to examine the effect of scour on a scale-model monopile was undertaken at a dense sand test site. Scour was found to have a noticeable effect on the natural frequency response of this foundation structure with a measured reduction in first natural frequency from $\approx 57.59 \mathrm{~Hz}$ to $7.42 \mathrm{~Hz}$ for $1.8 \mathrm{~m}$ or $5.3 \mathrm{D}_{\text {pile }}$ of (extreme) scour. This extreme scour was performed for the purpose of validating numerical finite-element models of the soil-pile system capable of tracking the change in the natural frequency of the system due to scour. These simple 1-D spring-beam numerical models were developed in MATLAB where the soil spring stiffness was modelled using small-strain stiffness $\left(\mathrm{G}_{0}\right)$ data obtained from in-situ tests such as MASW and CPT tests. 
A numerical model of a full offshore wind turbine and monopile foundation was developed using the same spring-beam modelling philosophy as that used to model the experiment. The purpose of this model was to investigate the effect of scour on the natural system frequency of a full-scale structure for a range of soil densities typically encountered in the offshore environment. The nacelle and rotor system was modelled as a lumped mass at the top of the tower. Typical tower and monopile geometric and material properties were used in the numerical model which corresponded approximately to a 3.6 MW offshore turbine. Three different soil stiffness profiles were developed corresponding to loose, medium dense and very dense sand. The effect of scour on the natural frequency of the system was obtained by removing springs sequentially from the model and performing an eigenvalue analysis for each removal stage. The loose sand stiffness profile demonstrated the largest relative change in frequency response with an overall reduction in natural frequency of the order of $8.5 \%$ for a design scour depth of $1.3 \mathrm{D}_{\text {pile }}$ compared to approximately $6.5 \%$ for very dense sand, suggesting that resonance effects are most likely in loose deposits.

Limitations in the numerical model include the fact that the gyroscopic effects of blade rotation have not been encompassed, which would have some effect on the dynamics of the system. Also, fluidstructure interaction effects around the exposed monopile and the potential build-up of pore pressures in the foundation soil due to the cyclic loading have not been accounted for in the numerical study. However, the model is still a reasonable approximation for the analysis of offshore turbines and moreover, the results suggest that the frequency response framework adopted provides a viable means of real-time remote monitoring of scour.

\section{Acknowledgements}

The authors would like to acknowledge the support of the Earth and Natural Sciences (ENS) Doctoral Studies Programme, funded by the Higher Education Authority (HEA) through the Programme for Research at Third Level Institutions, Cycle 5 (PRTLI-5), co-funded by the European Regional Development Fund (ERDF).

\section{References}

API, 2007. RP2A: Recommended practice for planning, designing and constructing offshore platforms - Working stress design. Washington, DC.

Ashford, S.A., Juirnarongrit, T., 2003. Evaluation of Pile Diameter Effect on Initial Modulus of Subgrade Reaction. Geotech. Geoenvironmental Eng. 129, 234-242. doi:10.1061/(ASCE)10900241(2003)129:3(234)

Augustesen, A.H., Brødbæk, K.T., Møller, M., Sørensen, S.P.H., Ibsen, L.B., Pedersen, T.S., Andersen, L., 2009. Numerical Modelling of Large-Diameter Steel Piles at Horns Rev, in: 
Proceedings of the Twelfth International Conference on Civil, Structural and Environmental Engineering Computing. pp. 1-14.

Brincker, R., Zhang, L., Andersen, P., 2000. Modal Identification from Ambient Responses using Frequency Domain Decomposition, in: Proceedings of 18th International Modal Analysis Conference.

Brincker, R., Zhang, L., Andersen, P., 2001. Modal identification of output-only systems using frequency domain decomposition. Smart Mater. Struct. 10, 441-445. doi:10.1088/0964$1726 / 10 / 3 / 303$

Chow, F.C., 1997. Investigations into displacement pile behaviour for offshore foundations. University of London, Imperial College.

Det Norske Veritas, 2007. DNV Offshore Standard DNV-OS-J101 Design of Offshore Wind Turbine Structures.

Det Norske Veritas, 2011. DNV Offshore Standard DNV-OS-J101 Design of Offshore Wind Turbine Structures.

Det Norske Veritas, 2013. DNV Offshore Standard DNV-OS-J101 Design of Offshore Wind Turbine Structures.

Dezi, F., Gara, F., Roia, D., 2012. Dynamic response of a near-shore pile to lateral impact load. Soil Dyn. Earthq. Eng. 40, 34-47. doi:10.1016/j.soildyn.2012.04.002

Doherty, P., Gavin, K., 2012. Laterally loaded monopile design for offshore wind farms. Proc. ICE Energy 165, 7-17. doi:10.1680/ener.11.00003

Doherty, P., Kirwan, L., Gavin, K., Igoe, D., Tyrrell, S., Ward, D., O’Kelly, B., 2012. Soil Properties at the UCD Geotechnical Research Site at Blessington, in: Proceedings of the Bridge and Concrete Research in Ireland Conference. Dublin, Ireland.

Donohue, S., Long, M., Gavin, K., O’Connor, P., 2004. Shear Wave Stiffness of Irish Glacial Till, in: International Conference of Site Characterisation I. Porto, Portugal, pp. 459-466.

Dutta, S.C., Roy, R., 2002. A critical review on idealization and modeling for interaction among soilfoundation-structure system. Comput. Struct. 80, 1579-1594. doi:10.1016/S00457949(02)00115-3

EWEA, 2012. The European offshore wind industry key 2011 trends and statistics.

Fahey, M., Lehane, B.M., Stewart, D., 2003. Soil Stiffness for shallow foundation design in Perth CBD. Aust. Geotech. J. 38, 61-90.

Gavin, K.G., Kirwan, L., Igoe, D., 2013. The effect of ageing on the axial capacity of piles in sand. Proc. ICE - Geotech. Eng. 166, 122-130.

Igoe, D., Gavin, K., O’Kelly, B., 2011. The shaft capacity of pipe piles in sand. J. Geotech. Geoenvironmental Eng. 137, 903-912.

Jardine, R.J., Chow, F.C., Overy, R.F., Standing, J., 2005. ICP Design Methods for Driven Piles in Sands and Clays. London. 
Ju, S.H., 2013. Determination of scoured bridge natural frequencies with soil-structure interaction. Soil Dyn. Earthq. Eng. 55, 247-254. doi:10.1016/j.soildyn.2013.09.015

Kwon, Y.W., Bang, H., 2000. The Finite Element Method using MATLAB. CRC Press, Inc., Boca Raton, FL.

LeBlanc, C., Houlsby, G.T., Byrne, B.W., 2010. Response of stiff piles in sand to long-term cyclic lateral loading. Géotechnique 60, 79-90. doi:10.1680/geot.7.00196

Lehane, B.M., 1992. Experimental investigations of displacement pile behaviour using instrumented field piles. University of London, Imperial College.

Lunne, T., Christopherson, H.P., 1983. Interpretation of Cone Penetrometer Data for Offshore Sands, in: Offshore Technology Conference OTC4464. Houston, Texas.

Matutano, C., Negro, V., López-Gutiérrez, J.-S., Esteban, M.D., 2013. Scour prediction and scour protections in offshore wind farms. Renew. Energy 57, 358-365. doi:10.1016/j.renene.2013.01.048

Murtagh, P.J., Basu, B., Broderick, B.M., 2004. Simple models for natural frequencies and mode shapes of towers supporting utilities. Comput. Struct. 82, 1745-1750. doi:10.1016/j.compstruc.2004.04.005

Negro, V., López-Gutiérrez, J.-S., Esteban, M.D., Matutano, C., 2014. Uncertainties in the design of support structures and foundations for offshore wind turbines. Renew. Energy 63, 125-132. doi:10.1016/j.renene.2013.08.041

Peder Hyldal Sørensen, S., Bo Ibsen, L., 2013. Assessment of foundation design for offshore monopiles unprotected against scour. Ocean Eng. 63, 17-25.

doi:10.1016/j.oceaneng.2013.01.016

Prendergast, L.J., Gavin, K., 2014. A review of bridge scour monitoring techniques. J. Rock Mech. Geotech. Eng. 6, 138-149.

Prendergast, L.J., Hester, D., Gavin, K., O'Sullivan, J.J., 2013. An investigation of the changes in the natural frequency of a pile affected by scour. J. Sound Vib. 332, 6685-6702. doi:http://dx.doi.org/10.1016/j.jsv.2013.08.020i

Robertson, P.K., 1997. Base load-displacement response of piles in sand. Can. Geotech. J. 27, 151158.

Schnaid, F., Lehane, B.M., Fahey, M., 2004. In situ test characterisation of unusual geomaterials, in: Proceedings of the International Conference of Site Characterisation. Porto, Portugal, pp. 49-73.

Sedlar, D., Lozina, Ž., Vučina, D., 2011. Experimental investigation of the added mass of the cantilever beam partially submerged in water. Teh. Vjesn. 18, 589-594.

Sørensen, S.P.H., Ibsen, L.B., Frigaard, P., 2010. Experimental evaluation of backfill in scour holes around offshore monopiles, in: Proceedings of the Second International Symposium on Frontiers in Offshore Geotechnics. Perth, Western Australia, pp. 617-622.

Sumer, B.M., Fredsøe, J., 2001. Scour around pile in combined waves and current. J. Hydraul. Eng. 127, 403-411. 
Sumer, B.M., Fredsøe, J., Christiansen, N., 1992. Scour Around Vertical Pile in Waves. J. Waterw. port, Coast. Ocean Eng. 118, 15-31.

Tedesco, J.W., McDougal, W.G., Allen Ross, C., 1999. Structural Dynamics: Theory and Applications.

Tempel, J. Van Der, Molenaar, D., 2002. Wind Turbine Structural Dynamics - A Review of the Principles for Modern Power Generation, Onshore and Offshore. Wind Eng. 26, 211-220.

Tolooiyan, A., Gavin, K., 2011. Modelling the Cone Penetration Test in Sand Using Cavity Expansion and Arbitrary Lagrangian Eulerian Finite Element Methods. Comput. Geotech. 38, 482-490. 